\title{
Design of marine protected areas in a human-dominated seascape
}

\author{
Simonetta Fraschetti ${ }^{1, *}$, Paolo D'Ambrosio ${ }^{1}$, Fiorenza Micheli ${ }^{2}$, Fausto Pizzolante ${ }^{1}$, \\ Simona Bussotti ${ }^{1}$, Antonio Terlizzi ${ }^{1}$ \\ ${ }^{1}$ Dipartimento di Scienze e Tecnologie Biologiche ed Ambientali (DiSTeBA), Università del Salento, CoNISMa, \\ 73100 Lecce, Italy \\ ${ }^{2}$ Hopkins Marine Station, Stanford University, Pacific Grove, California 93950, USA
}

\begin{abstract}
Conservation of the Mediterranean marine ecosystems is particularly challenging; high biodiversity is combined with high human population densities and a long history of resource exploitation. Residents and users of coastal areas often perceive marine conservation and management as limiting factors to economic development. Under these conditions, the creation of comprehensive systems of marine protected areas (MPAs) can be problematic. We selected a stretch of coast in southern Italy as a representative example of a Mediterranean coastline and nearshore marine ecosystems, featuring a complex matrix of vulnerable habitats in a landscape fragmented by multiple human activities and associated stressors. Through the use of site-selection algorithms, we investigated how human activities constrain MPA planning. Rather than assuming that patches of the same habitat found at different locations are interchangeable, we considered the scenario of a heterogeneous landscape of human impacts creating high variability in habitat quality. Despite widespread human influence, identification of portions of habitats to be protected from direct human disturbance as core no-take areas is still possible using the inclusion of 10 and $30 \%$ of low and high priority habitat, respectively, in reserves as a conservation target. Implementation of MPAs with a limited protection scheme that also include several small no-take areas could represent a feasible strategy for the conservation of Mediterranean coastal marine habitats. Moreover, MPAs could be combined with coastal zoning of activities as a means of further controlling effects over broader areas and allowing for recovery of degraded areas. Site-selection algorithms are invaluable tools for conservation planning. However, careful consideration of the potential constraints imposed by local human activities and future research aimed at filling existing gaps in understanding the ecology are crucial for making this approach useful in marine conservation planning.
\end{abstract}

KEY WORDS: Marine protected areas $\cdot$ Human impacts and constraints $\cdot$ Biodiversity $\cdot$ MARXAN · Mediterranean Sea $\cdot$ Site-selection algorithms $\cdot$ Marine seascapes $\cdot$ MPA networks

Resale or republication not permitted without written consent of the publisher

\section{INTRODUCTION}

The Mediterranean Sea presents major challenges for planning and implementing marine conservation measures. This semi-enclosed basin combines high levels of marine biodiversity and endemism with high human population densities, a long history of exploitation of marine resources and alteration of coastal habitats, and limited protection of marine ecosystems (Myers et al. 2000, Shi et al. 2005, Maiorano et al. 2006,
Halpern et al. 2008). Multiple threats to marine biodiversity overlap along Mediterranean coastlines and include coastal eutrophication, chemical pollution, increasing frequency of toxic and mucilaginous algal blooms, coastal armouring and engineering, and the use of destructive fishing gear (Airoldi \& Beck 2007). Furthermore, the coastline is fragmented by urban settlements and extensive coastal development, making the implementation of large continuous marine protected areas (MPAs) particularly problematic. Because 
of these challenges, which are shared by many densely populated regions worldwide, the development of a representative ecological network of Mediterranean MPAs (Agardy 2005) can be realistically considered a difficult target.

The establishment of ad hoc MPAs based on little or no scientific information and limited consideration of local stakeholder needs and perspectives is still the rule in the Mediterranean region (Fraschetti et al. 2005, Guidetti et al. 2008). As a consequence, local populations often perceive marine conservation and management as an obstacle to economic development, leading to widespread lack of compliance with MPA regulations (e.g. poaching) within established MPAs. The combination of these circumstances probably underlies the highly variable efficacy documented for Mediterranean MPAs (Claudet et al. 2008, Guidetti et al. 2008). For example, despite the large number of MPAs established along the Italian coastlines (25 to date, ranging in size between 120 and 53992 ha and protecting a total of 188000 ha along $604 \mathrm{~km}$ of coastline), a recent large-scale monitoring program highlighted that the majority of MPAs are not effective, either in terms of habitat representation or benefits to target fish populations (Fraschetti et al. 2005, Ceccherelli et al. 2006, Guidetti \& Sala 2007). Lack of enforcement has been identified as one of the most important causes of this widespread low efficacy (Guidetti et al. 2008). Simultaneous consideration of biodiversity conservation targets, the distribution of sources of impact, and the attitudes and perspectives of local stakeholders is crucial to make conservation effective. A new strategy for designing MPAs that would include a greater effort to inform the public and promote participation in the decision-making process, and would consider human presence and activities as an integral part of the system, is urgently needed.

The criteria used to select locations and sizes of individual MPAs have been extensively debated (Roberts et al. 2003). Site-selection algorithms have been initially applied in terrestrial environments and are especially suited to design MPA networks (Ball \& Possingham 2000, Rondinini \& Boitani 2006). These tools were recently adopted in MPA planning in several marine regions (Sala et al. 2002, Airamé et al. 2003, Leslie et al. 2003, Banks et al. 2005), providing an effective framework both for the evaluation of potential inefficiencies of existing systems and/or for planning new protection scenarios. Anthropogenic activities that potentially constrain MPA effectiveness were rarely incorporated into network design or, if they were incorporated, were included only as potential conflict with fishing activities (Sala et al. 2002, Leslie 2005, Richardson et al. 2006). Attempts to integrate biological and anthropogenic aspects of biodi- versity conservation are still uncommon (Fernandes et al. 2005, Klein et al. 2008, Tallis et al. 2008), and have never been applied in a multifaceted context such as seen in the Mediterranean Sea. To quantify the extent to which human activities can limit the identification of an MPA system in coastal densely populated areas, we decided to apply site-selection algorithms to a stretch of coast that could be considered a paradigmatic example of Mediterranean coastal areas represented by a complex matrix of vulnerable habitats and assemblages in a landscape fragmented by multiple stressors. Our goal was to design an MPA system that would include several small areas as high conservation priorities (no-take areas) on the basis of (1) high resolution, spatially explicit data on biodiversity distribution, (2) combination of different conservation targets for high and low priority habitats, and (3) realistic evaluation of human activities and potential sources of disturbance. The potential for support or opposition to MPA establishment by different stakeholders was also incorporated into site selection. We are aware that this approach does not ensure the creation of a functioning reserve system. The design of effective MPAs is still a complex matter, requiring a deeper understanding of ecosystem dynamics and more ecological research on conservation issues, marine management and sustained exploitation (Underwood 1995, Langlois \& Ballantine 2005). However, given the selection of appropriate criteria, the use of site selection algorithms can assist in MPA initial planning to avoid political conflicts typically leading to the suboptimal representation of critical habitats.

\section{MATERIALS AND METHODS}

Study area. We selected a $40 \mathrm{~km}$ stretch of coastline in the central Mediterranean Sea, between Otranto $\left(40^{\circ} 09^{\prime} \mathrm{N}, 18^{\circ} 29^{\prime} \mathrm{E}\right)$ and Santa Maria di Leuca $\left(39^{\circ} 47^{\prime} \mathrm{N}, 18^{\circ} 22^{\prime} \mathrm{E}\right)$, Apulia, Italy (Fig. 1), identified as a potential area for a future MPA (www.minambiente. it). Therefore, this study is not only a theoretical exercise, but is also likely to be instrumental in developing a process for site selection and implementation of an MPA. In a previous study, this area emerged as distinct in terms of composition and relative abundances of shallow subtidal benthic species compared with the broader Apulian coastline (Fraschetti et al. 2001). Coastal marine communities are highly diverse (Guidetti et al. 2002, Giangrande et al. 2003, Terlizzi et al. 2003, 2007) due to the presence of bioconstructions, seagrass meadows and submerged caves (Bussotti et al. 2006). The focal stretch of coastline is small when compared with previous areas developed for regional 


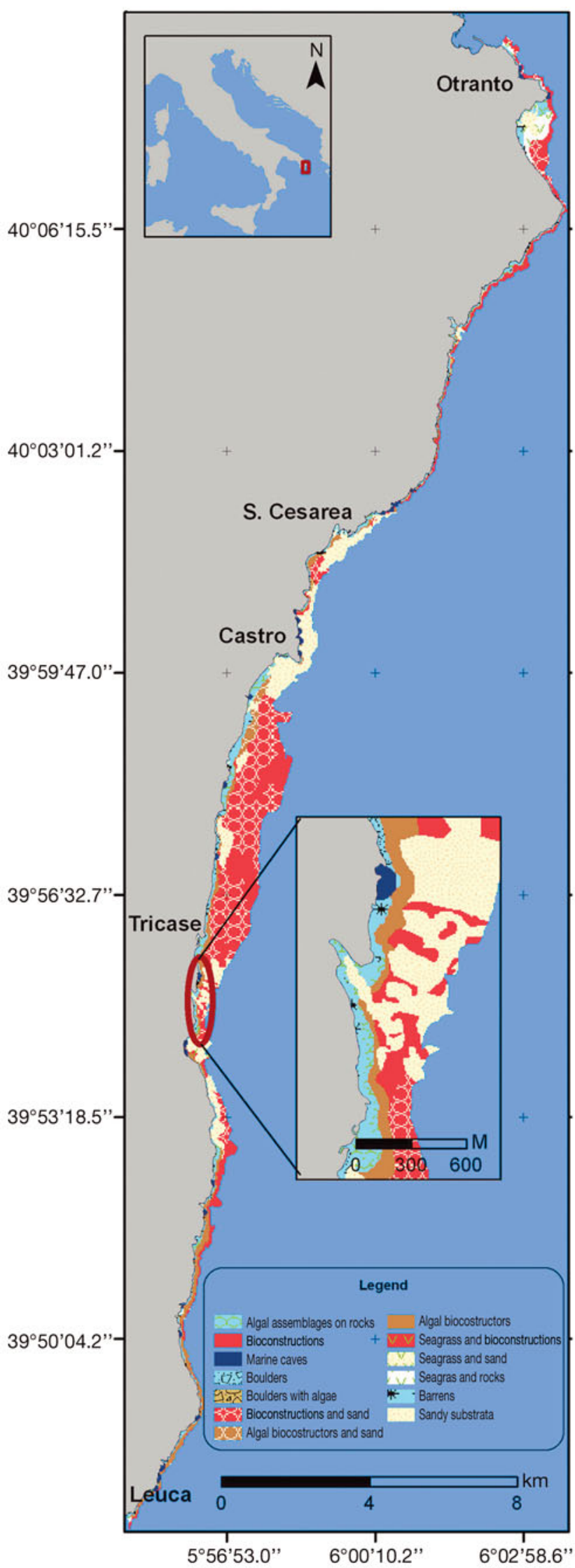

applications of quantitative procedures for network selection (see Sala et al. 2002, Airamé et al. 2003, Leslie et al. 2003, Banks et al. 2005). However, this spatial scale is representative of the high biological and socioeconomic heterogeneity and fragmentation that characterises Mediterranean coastlines. Approximately 66000 people live in this area, with population densities ranging from 70 to 631 people per $\mathrm{km}^{2}$ in 10 municipalities. Tourism is intense and strongly seasonal; the district of Otranto has approximately 8500 year-round residents, but hosts about 82000 tourists during the summer (www.pugliaturismo.com/ aptlecce).

Bathymetric and habitat mapping. A grid-based map was produced by digitizing the shoreline from a 1:10 000 scale map. The bathymetric map was obtained by spatial interpolation of data from approximately 500000 bathymetric points recorded during one extensive field survey (March 2004) that consisted of transects (spaced $150 \mathrm{~m}$ from each other) parallel and orthogonal to the shoreline. Depths were recorded by continuous data registration with a digital echo sounder and geographic coordinates were identified by a differential GPS. The georeferencing was provided according to the GAUSS-BOAGA (Italian national grid) coordinate system.

Benthic habitats were mapped in March to October 2004. Overall, more than 6000 points were registered along 160 transects (approximately 2 transects $\mathrm{km}^{-1}$ of coastline) from the surface to $30 \mathrm{~m}$ depth (approximately $2 \mathrm{~km}$ offshore). Free divers (often using underwater scooters) performed the data acquisition at each point. For a better characterisation of the distribution of benthic habitats and assemblages and a more precise definition of the map the number of transects was occasionally increased in case of sharp discontinuities (in terms of substrate morphology). Data acquired during this survey were superimposed to 11 aerial digital orthophotos (2005, resolution 1:5000). Identification of habitats was based on the features that create structural complexity, such as plants (e.g. seagrass meadows), animals (bioconstructors) or geological features (rocky reefs, sandy substrate) (Fraschetti et al. 2008). Habitats were used as surrogates for biodiversity and were the only conservation features considered. Thirteen habitat types were identified (Fig. 1, see Table 1). The surface area of each habitat patch was calculated using ArcGis 8.1, combining data from bathymetry and habitat mapping.

Fig. 1. Distribution of biodiversity with the georeferenced distribution of different habitat types. The enlargement shows the patchy distribution of habitats and assemblages. The inset indicates location of the study area in southern Italy 


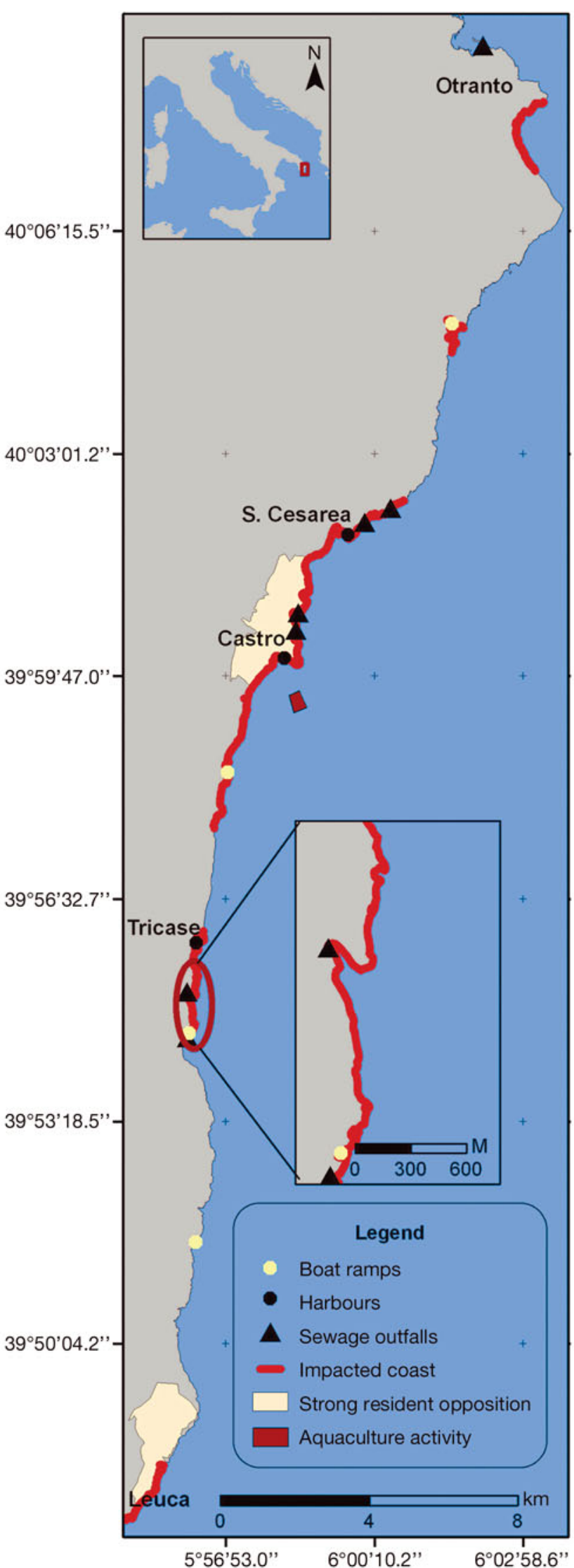

Distribution of human activities and residents' attitudes. We mapped the distribution of harbours, marinas, coastal developments, boat ramps, sewage outfalls, aquaculture farms and areas used for recreational activities by conducting extensive in situ surveys by boat (Fig. 2). Fishing activities (both recreational/artisanal and commercial) were observed and georeferenced during biological sampling. Distribution of each anthropogenic activity was added as layers in ArcGis 8.1.

Fishing, aquaculture, sewage discharge and distribution of harbours, marinas and tourism infrastructures were the dominant anthropogenic activities that potentially could be affected by MPA establishment or could affect MPA planning and were included as variables in the analyses. The extent and potential effect of these activities on habitat and assemblages were not directly assessed, but derived from the literature for comparable locations and intensities of disturbance (Terlizzi et al. 2005, Benedetti-Cecchi \& Osio 2007, Pusceddu et al. 2007).

We assessed stakeholder attitudes and potential support for MPAs by interviewing 4 categories: recreational/artisanal fishers, commercial fishers, hotel owners and restaurant owners, for a total of 240 interviews. Interviews were semistructured, allowing for conversational, 2-way communication. Interviews were conducted between February and June 2005. An example of the questionnaire used is available in Appendix 1 at www.int-res.com/articles/suppl/ m375p013_app.pdf. Fisher information (number and type of registered vessels) was obtained from local maritime offices (Otranto, Castro, Tricase Porto, S. M. di Leuca). The Tourism Promotion Agency of the Lecce Province (www.pugliaturismo.com/aptlecce) provided a complete list of hotel and restaurant owners. For each stakeholder category, interviews were conducted with over $70 \%$ of people listed. Crossed controls were carried out between fisher lists provided by maritime offices and those provided by fishers' cooperatives to check for data completeness. The sample of tourism operators was randomly selected from the list provided by the Tourism Promotion Agency and compared with statistics provided by the Lecce Statistical Office (http://comune.lecce.it). All fishers were male and tourism operators had approximately equal male-female representation.

Site-selection procedures. The software MARXAN (Ball \& Possingham 2000, Possingham et al. 2000; www.ecology.uq.edu.au/marxan.htm, accessed September 2008) was used for site selection. This algorithm relies on static distribution patterns of biodiver-

Fig. 2. Distribution of human activities with the georeferenced distribution of the different sources of anthropogenic disturbance and residents' attitudes towards MPAs 
sity (species, habitats, landscape types) to identify, prioritise and select candidate sites for MPAs in the framework of resource management in terrestrial, freshwater and marine ecosystems. It has the advantage of minimising the number of sites or the area of the MPA system while meeting fixed targets for biodiversity conservation.

Different combinations of biological, economic and social criteria have been proposed for the selection of locations for MPA institution (Roberts et al. 2003). We limited our focus on the consequences of using different combinations of conservation targets or representation of different habitat types while minimising the extent of the fully protected areas needed to achieve habitat representation. Rather than assuming that patches of the same habitat are interchangeable, we considered the scenario of a heterogeneous landscape of human impacts creating high variability in betweenand within-habitat quality. The ecological goal was to maximise the conservation of priority habitats while minimising the risk of including sites where the presence of potential threats to biodiversity from human activities could limit the efficacy of protection.

We subdivided the study area into 2603 planning units, $100 \times 100 \mathrm{~m}$ in size, by imposing a selection grid over the maps resulting from the combination of the above data. The size of the planning units was decided according to the length of the focal stretch of coastline. Each planning unit included one or more habitat types in addition to the presence or absence of the human activities described above. We evaluated the importance of potential human threats in conservation planning by using different conservation targets, combined with information on the presence of human activities (fishing, aquaculture, sewage discharges, harbours and marinas and distribution of tourism infrastructures).

The protection of $20 \%$ of a proposed area is a common target in marine conservation (Sale et al. 2005). However, this target is arbitrary and no general scientific agreement exists on what this threshold should be (Stewart et al. 2007). Because of this lack of knowledge about which conservation targets should be selected to protect comprehensive and representative samples of biodiversity, we used a range of different targets.

We first used a 100\% conservation target for each habitat in combination with the presence of anthropogenic activities to assess the extent to which these activities limit the habitat's potential to meet the conservation target and in which habitats these limitations occur; a $100 \%$ target (i.e. the entire area is included in the MPA) is clearly unrealistic. The adoption of a $35 \%$ target was recently recommended based on estimates of the fraction of natural egg production that sustains fish populations (Airamé et al. 2003, Botsford et al. 2003). In this stretch of coastline, habitats vary in terms of biodiversity and potential vulnerability to anthropogenic disturbance, so we used a combination of different conservation targets, either $30 \%$ or $10 \%$ for the low priority habitats, and $50 \%$ or $30 \%$ for the high priority habitats. High priority habitats were characterised by fragile, long-lived species and high species richness, e.g. bioconstructions and seagrass meadows consisting of Posidonia oceanica (see Table 1). Low priority habitats were relatively common, characterised by short-lived species or low biotic cover and diversity, e.g. shallow algal assemblages and sandy bottom habitats, respectively. There is little empirical evidence that the anthropogenic activities considered here have different effects on high and low priority habitats. Our decision to set different conservation targets for high and low priority habitats was made on the basis of their commonness or rarity and the likely time frames for recovery from effects associated with life history characteristics of the inhabiting organisms. Recent studies on a subset of submerged caves of this area (Bussotti et al. 2002, 2006) showed that unique benthic assemblages characterise each cave, and that caves are important as nurseries for some fish species, so they were considered as high priority habitats. The upper target was always higher than the commonly used $20 \%$ because catch-log data for this area revealed clear signs of overfishing, with total catches decreasing from $1433479 \mathrm{~kg}$ in 1995 to $251852 \mathrm{~kg}$ in 2000 . Because of such intense human pressure, targets greater than $20 \%$ were used.

The amount of each conservation feature (in our case the amount of habitat expressed as surface area, in $\mathrm{m}^{2}$ ) was included in the 'conservation feature distribution file' for MARXAN runs. Alternative scenarios were obtained by setting different representation targets in the 'conservation feature file': $100 \% ; 10$ and 30\% for low and high priority habitats, respectively; or 30 and $50 \%$ for low and high priority habitats, respectively, of the total amount of habitats mapped in the area. We also assigned a penalty factor for not achieving the specified conservation target for the 3 highest priority habitats: bioconstructions, seagrass and submerged caves. The effects of the combination of different conservation targets $(100 \%, 10$ and $30 \%$, and 30 and $50 \%$ ) on the MPA network configuration were analysed by ignoring or incorporating anthropogenic activities. Thus, in the 'planning unit file', planning units containing fishing (both recreational/artisanal and commercial), aquaculture activities, harbours, marinas, sewage outfalls, boat ramps and stretches of coast characterised by coastal development and intense recreational use, or by strong resident opposition to areas with high conservation priorities, were excluded from all scenarios by setting the value in the status field of the planning unit file to 3 . 
Table 1. Habitat types and their surface areas under alternative scenarios resulting from different combinations of conservation goals $(100 \%, 10$ and $30 \%$ for low and high priority habitats, respectively, or 30 and $50 \%$ for low and high priority habitats, respectively), and ignoring or incorporating (+A) anthropogenic activities and attitudes towards MPAs. Total habitat area is expressed in ha, whereas results for each scenario are expressed as percentages (\%) of total areas for each habitat type

\begin{tabular}{|c|c|c|c|c|c|c|}
\hline Habitat type & $\begin{array}{c}\text { Total habitat } \\
\text { area (ha) }\end{array}$ & $\begin{array}{c}\text { Scenario A } \\
100 \%+A\end{array}$ & $\begin{array}{c}\text { Scenario B } \\
10 / 30 \%+A\end{array}$ & $\begin{array}{c}\text { Scenario C } \\
10 / 30 \%\end{array}$ & $\begin{array}{l}\text { Scenario D } \\
30 / 50 \%+A\end{array}$ & $\begin{array}{c}\text { Scenario E } \\
30 / 50 \%\end{array}$ \\
\hline Algal assemblages on rocks & 105.2 & $26.0^{\mathrm{a}}$ & 12.6 & 20.8 & $26.0^{\mathrm{a}}$ & $28.4^{\mathrm{a}}$ \\
\hline Algal bioconstructions & 195.3 & $43.8^{\mathrm{a}}$ & 28.2 & 28.7 & $43.1^{\mathrm{a}}$ & $47.1^{\mathrm{a}}$ \\
\hline Algal bioconstructions and sand & 38 & $55.5^{\mathrm{a}}$ & 30.3 & 35.6 & 50.8 & 51.5 \\
\hline Barrens & 55.6 & $42.4^{\mathrm{a}}$ & 26.4 & 29.3 & 42.4 & 44.1 \\
\hline Barrens with algae & 112 & $36.9^{\mathrm{a}}$ & 11.8 & 19.5 & $27.5^{\mathrm{a}}$ & $27.6^{\mathrm{a}}$ \\
\hline Bioconstructions & 308.1 & $64.1^{\mathrm{a}}$ & 29.9 & 36.2 & 50.3 & 49.5 \\
\hline Bioconstructions and sand & 671.7 & $65.9^{\mathrm{a}}$ & 29.9 & 32.7 & 49.9 & 77.6 \\
\hline Boulders & 6.6 & $63.6^{\mathrm{a}}$ & 25.8 & 32.8 & 51.1 & 48.1 \\
\hline Marine caves & 31 & $47.1^{\mathrm{a}}$ & 42.9 & 42.9 & $46.9^{\mathrm{a}}$ & 72.5 \\
\hline Sandy substrata & 387.4 & $26.9^{\mathrm{a}}$ & 9.9 & 15.2 & $26.8^{\mathrm{a}}$ & 29.6 \\
\hline Seagrass and bioconstructions & 3.5 & $51.4^{\mathrm{a}}$ & 41.1 & 35.4 & 50.3 & 98.9 \\
\hline Seagrass and rocks & 47.5 & $78.1^{\mathrm{a}}$ & 30.1 & 35.5 & 57.6 & 50.1 \\
\hline Seagrass and sand & 10.6 & $62.3^{\mathrm{a}}$ & 33.0 & 39.6 & 51.8 & 54.1 \\
\hline
\end{tabular}

To achieve a desired level of compactness, that is, to reduce the fragmentation of the network in many small patches that would be difficult to enforce, we used the boundary length modifier (BLM) to minimize both MPA-system boundary length and costs. In all scenarios, we reduced the fragmentation of high priority conservation areas (e.g. decreased the number and increased the average size of areas) by setting the MARXAN boundary length modifier to 1 . The value of the boundary length modifier was increased up to 5 in additional simulations (results not shown) without any improvement in the configuration.

A 2-way ANOVA was carried out on the number of planning units selected by each independent run of the algorithm, from the summary file generated by MARXAN, to test whether the total size of the high priority conservation areas was significantly affected by the use of different conservation targets (10 and 30\%, 30 and $50 \%$ ), and whether those differences were consistent when incorporating or ignoring anthropogenic activities. The $100 \%$ protection target was not included since it is not realistic. The ANOVA model included the factors: conservation target (fixed, 2 levels) and anthropogenic pressure (fixed, 2 levels, present or absent), with $\mathrm{n}=600$ for each combination of factors (SAS statistical package v8.1, SAS Institute).

Pressey's measure of efficiency described how efficiently representation targets are met under different scenarios (Pressey \& Nicholls 1989, Stewart et al. 2003). Efficiency was calculated as: $E=1-X / T$, where $X$ is the number of planning units needed to meet the constraints and $T$ is the total number of planning units.

We selected the following analysis input parameters: algorithm type, simulated annealing; number of simu- lations, 600; iterations per simulation, 100 000; number of temperature decreases per simulation, 10000; and choice of the initial temperature and cooling factor, adaptive.

\section{RESULTS}

Of the 240 interviews, 136 involved tourism operators (e.g. hotel or restaurant owners) while 104 were fishers (86 recreational/artisanal and 18 commercial fishers). The 2 categories were characterised by large differences in average age (lower in the tourism sector) and education level (lower for fishers). Of the interviewed residents involved in tourism-related activities, $66.2 \%$ declared total support for a generic implementation of an MPA (i.e. without specifying its size and location). Partial support was declared by $23 \%$ of this category. Economic benefits (27\% of the interviews) and increased value and attractiveness of the coast $(25 \%)$ were the most commonly anticipated consequences of the institution of the MPA. These percentages did not change when questions referred to the institution of an MPA on their stretch of coast.

Of all fishers (all residents in the area) $41 \%$ declared their total support for a generic implementation of an MPA, but this percentage decreased to $25 \%$ in the case of local MPA institution within their fishing areas. While all fishers answered that conservation of the marine environment is crucial, only $1.2 \%$ of them identified MPA institution as a potential solution for its protection.

This percentage increased to $7 \%$ for the tourism operators. A more detailed analysis showed significant spa- 
tial variation in responses, with significant differences in perception among residents living a few kilometres apart from each other. Even along a relatively small portion of coastline (approximately $40 \mathrm{~km}$ ), there was an interspersion of districts (featuring intense tourism activities) supportive of the implementation of MPAs and those with a strong fishing tradition that were strongly opposed to MPAs (Fig. 2, and Fig. A1 at www.int-res. com/articles/suppl/m375p013_app.pdf).

Along the selected coastline, the shore hosts a mosaic of subtidal habitats (Table 1, Fig. 1) superimposed on a steep depth gradient and interspersed in space. The dominant habitat types in terms of surface were bioconstructions and sandy substrates (approximately 28 and $20 \%$ of the total, respectively, plus a $34 \%$ mosaic of the two). Seagrass meadows (Posidonia oceanica) were less abundant and covered only $3 \%$ of the total area. Coralline barrens and macroalgaldominated assemblages were highly interspersed and represented $14 \%$ of the total. Finally, 31 submerged caves were identified.

The effects of increasing representation targets that both ignore and incorporate the presence of anthropogenic activities is presented in Table 1. Scenario A (conservation target at $100 \%$ for each habitat type) shows that human activities affect all habitats, even the scarcely represented ones. The habitats that commonly overlap with human activities were sandy bottoms, shallow algal assemblages, sea urchin barrens with algal patches and submerged caves, as indicated by the large difference between habitat extent and amount of habitat included in the network of no-take areas once constraints from human activities were included. The least affected habitats were Posidonia oceanica meadows on sandy and rocky bottoms, bioconstructions, patches of bioconstructions on sand, and boulders.

At the lower representation target (10 and 30\% for low and high priority habitats, respectively), a greater percentage of habitats was included in the scenario without anthropogenic activities than in the scenario including them, with the only exception being seagrass meadows and bioconstructions (Table 1). Increasing conservation targets from 10 and $30 \%$ to 30 and $50 \%$ resulted in larger extension of all the habitats being included in no-take areas, and representation targets were generally achieved for most habitats. Targets were not met for algal assemblages on rocks, algal bioconstructions and barrens with algae, even though the discrepancy was small (Scenario E). When human activities were included, targets were still met for all habitats for the 10 and $30 \%$ target (Scenario B, Table 1). The inclusion of anthropogenic activities caused a further fragmentation of the network with an increase in the number of small areas identified as high conservation priorities in the southern portion of the shoreline (from 9 to 13; Fig. 3, Table 2).

In contrast, the 30 and $50 \%$ conservation targets for low and high priority habitats, respectively, were not met in several habitats when human activities were included (Scenario D). Setting a 30 and $50 \%$ conservation target while simultaneously accounting for anthropogenic activities resulted in a network of small areas that did not achieve the target set for algal assemblages, barrens with algal patches, algal bioconstructions and sandy bottoms. In addition, submerged caves were affected by the inclusion of anthropogenic activity constraints, and, in fact, the total surface of no-take areas was $30 \%$ lower than the total surface of the network identified without considering human activities (Scenarios D versus E in Table 2).

Increasing the representation target without considering the effects of human activities had the result of creating a network composed of fewer, but larger areas (Table 2). For example, Scenario E shows a large area in the middle of the coastline (MPA 5; Fig. 3, Table 2), reaching 894.8 ha. Similar to the 10 and $30 \%$ conservation targets, even at a 30 and $50 \%$ target the inclusion of the presence of human activities (Scenario D) has the consequence of fragmenting this area into 3 smaller areas (MPAs 8, 9 and 10; Table 2). In addition, inclusion of anthropogenic activities resulted in best solution MPAs, spatially separated from the coastline (e.g. MPAs 2, 7, 8 and 10 in Scenario D; Fig. 3). This MPA configuration would make enforcement difficult and should be avoided when possible.

Despite variation in the number and size of areas among the scenarios considered, some areas were consistently selected across scenarios. In particular, a small offshore area in the northern region (MPA 1 in Scenarios A, C and E, MPA 3 in Scenario B, MPA 2 in Scenario D), a large coastal area in the centre (MPA 5 in Scenarios A, C and E, MPA 7 in Scenario B, and MPA 9 in Scenario D), and a small coastal area in the south (MPA 7 in Scenarios A, C and E, MPA 9 in Scenario B, MPA 11 in Scenario D) were consistently selected, despite variation in the actual size and shape (Fig. 3). This result largely depended on a combination of biological features of the selected areas, such as an abundance of patches of bioconstructions interspersed with seagrass meadows, and submerged caves (the high priority habitats). All these areas coincided with locations where interviews revealed residents' support for MPA institution, making them high conservation priorities both from a biological and socioeconomic standpoint.

The ANOVA of the total number of planning units for high conservation priorities under different scenarios showed a significant target $\times$ anthropogenic activity interaction $\left(F_{1,2396}=25.0, \mathrm{p}<0.0001\right)$, indicating that 

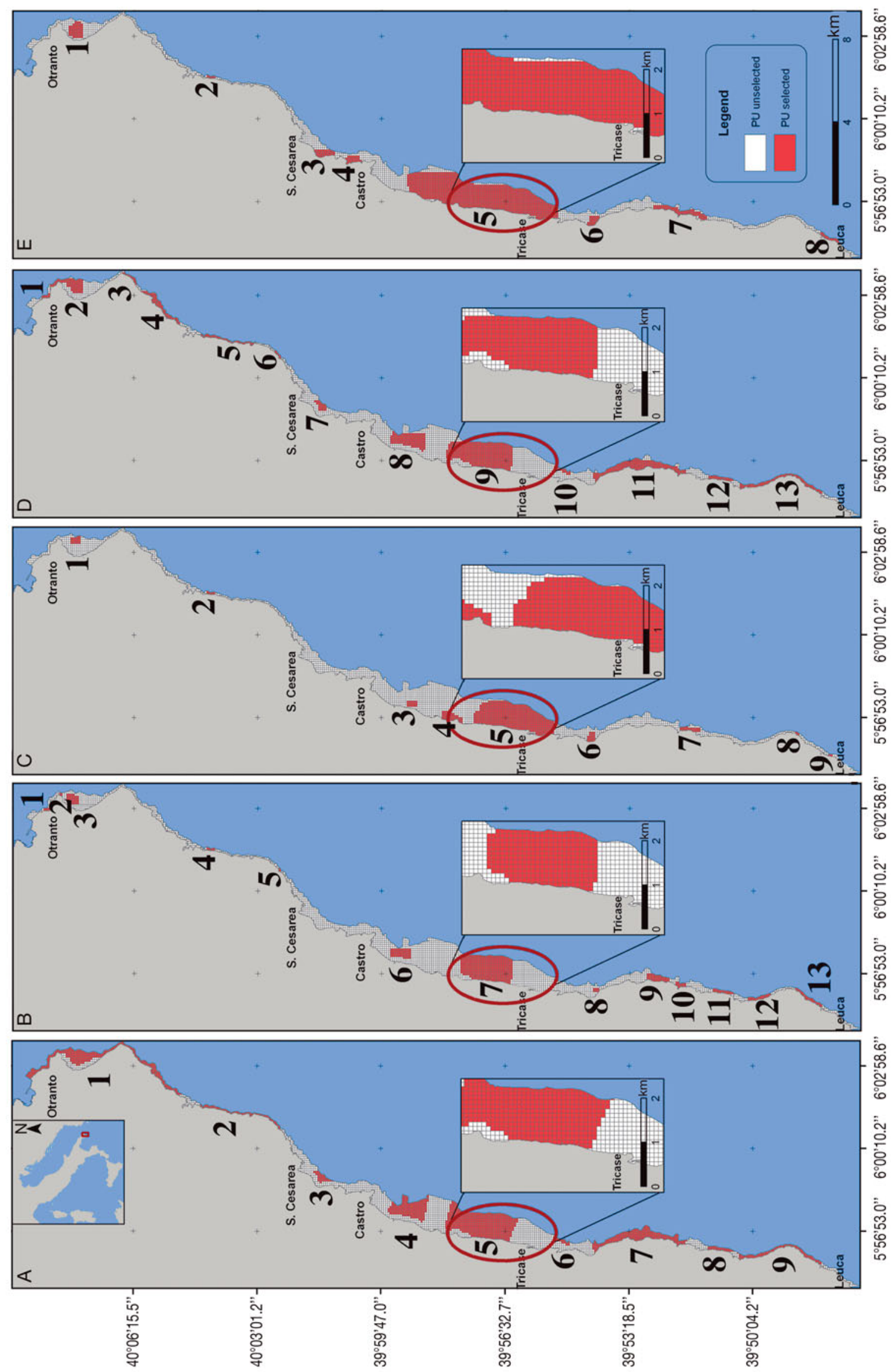

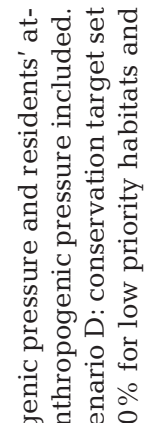

정

节完要

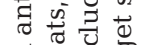

舟:

3.0 의

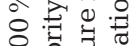

-1 .

준.

o to

矛递焉

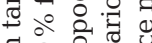

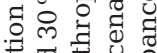

可 든

बै

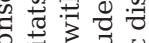

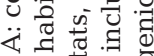

을

. 의

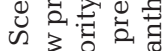

ते

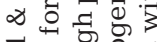

पㅇำ

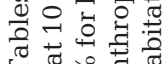

西。范

\&

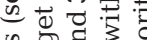

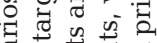

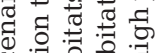

㻤 중

ᄃ웡

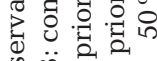

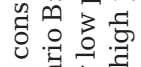

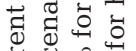

य్山

击

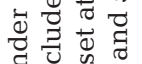

马.

o 0

过记

$\Phi$ 过

क तै त्र

远

过告

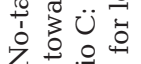

ले चै वे

롤 
Table 2. Effects of the combination of different conservation targets $(100 \%, 10$ and $30 \%$ for low and priority habitats, respectively, or 30 and $50 \%$ for low and high priority habitats, respectively), ignoring and incorporating $(+\mathrm{A})$ human activities, on the configuration of the network (values are surface areas of individual no-take areas selected in ha). In the first column, numbers 1 to 13 represent the selected no-take areas. See Fig. 3 for their locations

\begin{tabular}{|lccccc|}
$\begin{array}{l}\text { No-take } \\
\text { area }\end{array}$ & $\begin{array}{c}\text { Scenario A } \\
100 \%+\mathrm{A}\end{array}$ & $\begin{array}{c}\text { Scenario B } \\
10 / 30 \%+\mathrm{A}\end{array}$ & $\begin{array}{c}\text { Scenario C } \\
10 / 30 \%\end{array}$ & $\begin{array}{c}\text { Scenario D } \\
30 / 50 \%+\mathrm{A}\end{array}$ & $\begin{array}{c}\text { Scenario E } \\
30 / 50 \%\end{array}$ \\
\hline 1 & 193.5 & 3.8 & 16.6 & 6.3 & 48 \\
2 & 35.3 & 2.9 & 4.7 & 60.5 & 4.7 \\
3 & 23.1 & 27 & 15 & 8.1 & 29.23 \\
4 & 140.1 & 4.7 & 34.2 & 41.5 & 22.30 \\
5 & 382.6 & 1.4 & 408.46 & 22.8 & 849.85 \\
6 & 11.27 & 44 & 16.71 & 4.1 & 21.14 \\
7 & 149 & 291 & 18 & 18.5 & 56.24 \\
8 & 17.8 & 5.8 & 2.4 & 105.9 & 12.6 \\
9 & 54.9 & 30.9 & 1.8 & 349.4 & \\
10 & 10 & 11.3 & & & \\
11 & 14.2 & 134.6 & & & \\
12 & 16.1 & 17.5 & & & \\
13 & 19.3 & 54.4 & & & \\
\hline
\end{tabular}

demonstrate the gap in knowledge we still have in marine conservation. Planning and evaluation of conservation measures still lack basic ecological information, which is crucial for making effective conservation actions.

The main effect of including constraints by excluding from MPAs portions of habitats affected or actively used by residents is a considerable fragmentation of the areas selected as high conservation priorities. Such fragmentation decreases spatial efficiency and increases the costs and difficulty of enforcement of regulations within MPAs. Several small areas were selected even when representation targets were met for all habitat types. Thus, even though it was still possible to find solutions protecting the targeted total extent and representation of marine

the number of planning units in the different scenarios varied significantly with the inclusion or exclusion of human activities as constraints in the selection procedure. In particular, including anthropogenic activities resulted in a greater decrease of planning units selected at lower (10 and 30\% scenario: 611.3 versus 547.8 planning units selected, respectively, on average) compared with higher (30 and 50\% scenario: 1122.3 versus 1078.1 units, respectively) targets. In addition, variation in the number of planning units selected in different scenarios is much smaller when anthropogenic activities are included ( $\mathrm{SD}=5.1$ to 5.5 , across 600 simulations) than when these are not included ( $\mathrm{SD}=64.9$ to $67.7,600$ simulations), suggesting that inclusion of human activities constrains the selection procedure to a smaller range of possible options.

Finally, the measure of efficiency showed a decreasing trend in the efficiency of setting the alternative scenarios, with the highest efficiency value (0.8) reached by the 10 and $30 \%$ scenario, ignoring the effects of human activities, and the lowest (0.5) in the 30 and $50 \%$ target that included anthropogenic activities.

\section{DISCUSSION}

Our results illustrate the challenges of reconciling marine conservation with multiple human uses of coastal marine seascapes in densely populated regions, and the utility of systematic approaches for integrating biological information, data related to human activities and the stakeholder perception of conservation planning. However, at the same time, our analyses clearly habitats, this target could only be achieved through a network made up of very small no-take areas. Many existing MPAs in the Mediterranean Sea and elsewhere are indeed small (over half of the MPAs considered in a recent review range from 1 to $10 \mathrm{~km}^{2}$, with a median of $4 \mathrm{~km}^{2}$; Halpern 2003). Some evidence suggests that MPA size is less crucial than other factors in affecting protection effects, at least in fish populations (Côté et al. 2001, Guidetti \& Sala 2007, Guidetti et al. 2008), even though Claudet et al. (2008) demonstrated that increasing the size of the no-take zone increases the density of commercial fish species within the reserve compared with that outside of it. In the case of habitat formers and bioconstructors, even small MPAs can be effective in protecting the physical structure and ecological function (e.g. as nursery grounds for fish and invertebrates) of these habitats (Beck et al. 2001, Halpern 2003). Moreover, even species with high dispersal abilities can respond to protection in MPAs when fishing pressure outside MPAs is high (Micheli et al. 2004).

The high degree of fragmentation within the MPA could not be avoided by increasing the boundarylength modifier (i.e. by imposing a high degree of 'compactness' of individual areas in the site-selection procedures), indicating that, in this region, widespread anthropogenic activities result in a mosaic of habitat patches affected to varying degrees. This result is likely to apply to larger spatial scales as well, relative to the local scale considered in our analysis. The entire western Mediterranean coastline is embedded in a human dominated landscape making the selection of appropriate scales for conservation and management difficult (Palumbi 2004). Different patches of the same 
habitat were not considered to be interchangeable. Instead, we considered the more realistic scenario of a heterogeneous landscape of human impacts that creates high variability in between- and within-habitat quality. As a first step, we showed that it is possible to design an MPA system that includes small no-take areas using a 10 and $30 \%$ conservation target for low and high priority habitats that contains patches of habitat relatively undisturbed from local activities. If MPAs do not reach the coast, then this could further decrease the conflicts with a majority of resource users that concentrate their activities along the coastline. However, this MPA configuration also creates challenges for effective enforcement because monitoring activities in such MPAs could not be conducted from the shore, and users could not easily use landmarks to determine the location of MPA boundaries. The advantages and disadvantages of these specific aspects of reserve design would have to be evaluated case by case. Thus, the next step will be to assess the overall efficiency of such a spatial distribution of no-take areas in protecting marine biodiversity, with the possibility of rezoning and expanding the size of no-take areas to further mitigate the potential effects of human activities and address possible issues with enforceability of protection.

Our approach also provides a framework for assessing the efficacy of marine conservation. Such assessments have proved difficult because of lack of replication and proper controls (Fraschetti et al. 2002). Instead of selecting a unique location to be protected, we create a system of representative and replicated MPAs allowing properly replicated areas for long-term monitoring of the effectiveness of this protection.

The decision of assigning a penalty for not achieving the conservation target only in a subset of habitats stems from the awareness that not all habitats have equal structural and functional roles in marine ecosystems. Bioconstructions, seagrasses and submerged caves are important in terms of animal biomass export via movement of individuals, refuge from predation for mobile organisms, or outwelling of dissolved and particulate organic matter and production of carbonate particle (Canals \& Ballesteros 1997, Beck et al. 2001, Guidetti \& Bussotti 2002). Thus, a priori inclusion of high conservation targets for these habitats in all scenarios acknowledges their ecological importance. To date, seagrasses and submerged caves are the only marine habitats considered for special protection within the European Community (Habitat Directive 92/43 EEC). In contrast, although bioconstructions (the Mediterranean equivalent of tropical coral reefs) are affected by diving and fishing activities (Garrabou et al. 1998), they are not specifically targeted by conservation initiatives.
Targets imposing inclusion of $50 \%$ of the most diverse and fragile habitats resulted in increased surface areas for some areas, but also in a decrease in the efficiency of the system (Stewart et al. 2003). When anthropogenic activities were incorporated, representation targets were no longer met for some habitats, including submerged caves. Even though the 20\% conservation target commonly used in previous efforts may be ecologically inadequate (Sale et al. 2005), within human-dominated seascapes this may be a realistic target for no-take areas that combine both biological and social effectiveness. Since under these conditions, large continuous MPAs may not be feasible, marine conservation and management in densely populated regions needs to combine networks of small notake areas with coastal zoning of activities as a means of controlling effects over broader areas and allowing for recovery of degraded areas affected by multiple human impacts. Despite human influence, identification of habitat patches with low levels of impact to be protected from future human disturbance as core MPAs is still possible. Thus, systematic selection procedures provide useful guidance even in a complex context characterised by a matrix of vulnerable habitats and assemblages embedded in a highly fragmented human landscape.

Rather than being prescriptive, our application of site-selection procedures aims at being pragmatic and informative, illustrating how consideration of anthropogenic activities, users' attitudes and likelihood of local support for marine conservation influence the alternatives for MPA networks in coastal areas. This study, thus, represents an effort of conservation assessment to be translated into effective actions. Our results highlight high priority locations as core sites, both from a biological and a socioeconomic perspective. The actual number and shape of no-take areas and size of proposed networks will probably be influenced by additional considerations, such as ease of enforcement and administrative costs (e.g. possibly requiring a reduction of the number of selected areas).

A limitation of this approach is that it does not incorporate a measure of error and requires a great confidence in the chosen rules. Several decisions went into setting the targets and constraints guiding simulations under different scenarios. We set conservation targets based on recommendations from previous studies (Botsford et al. 2003) and existing information about the diversity and vulnerability of different Mediterranean habitats, based largely on expert opinion and local studies. The values and criteria should be modified according to different contexts, with additional quantitative studies directly addressing this issue.

Management and conservation of marine ecosystems remains a daunting challenge. Site-selection 
algorithms are valuable tools that can integrate disparate types of information used for initial steps in conservation planning. However, site-selection procedures do not account for the system dynamics and possible feedbacks that an MPA's implementation would trigger (Sanchirico \& Wilen 2001) and need high quality data for providing scientifically defensible scenarios of protection. Reducing these uncertainties will require combining modelling efforts with long-term ecological and socioeconomic monitoring programs, inclusion of the social dimension in MPA design and process-based studies directly addressing the effectiveness of protection schemes.

Acknowledgements. Support for S.F. was provided through the agreement between Stanford University (USA) and the University of Salento (Italy). This research was conducted as part of a PhD dissertation by P.D. Support for F.M. was provided through National Science Foundation (OCE01199776) and Environmental Protection Agency (R832223) grants. The authors acknowledge the support by the European Union: Interregional Cooperation Interreg II Italy-Greece, Integrated Project Sustainable Development, Global Change and Ecosystems (SESAME), Centro Euro-Mediterraneo per i Cambiamenti Climatici project (CMCC) and Modelli Integrati di Gestione Ottimale delle Risorse Ittiche di Acquicoltura della regione Puglia (MIGORIAP) projects. The network of excellence Marine Biodiversity and Ecosystem Functioning (MARBEF) funded by the European Community Sixth Framework Programme (contract no. GOCE-CT-2003-505446) provided additional support. F. Terlizzi produced the bathymetric maps. C. Vaglio and D. Fiorentino provided invaluable assistance during fieldwork.

\section{LITERATURE CITED}

Agardy T (2005) Global marine conservation policy versus site-level implementation: the mismatch of scale and its implications. Mar Ecol Prog Ser 300:242-248

Airamé S, Dugan JE, Lafferty KD, Leslie H, McArdle DA, Warner RR (2003) Applying ecological criteria to marine reserve design: a case study from the California Channel Islands. Ecol Appl 13:170-184

Airoldi L, Beck MW (2007) Loss, status and trends for coastal marine habitats of Europe. Oceanogr Mar Biol Annu Rev 45:347-407

Ball IR, Possingham HP (2000) MARXAN (V1.8.2). Marine reserve design using spatially explicit annealing. The Great Barrier Reef Marine Park Authority, Townsville, Australia

Banks SA, Skilleter GA, Possingham HP (2005) Intertidal habitat conservation: identifying conservation targets in the absence of detailed biological information. Aquat Conserv 15:271-288

Beck MW, Heck KL Jr, Able KW, Childers DL and others (2001) The identification, conservation and management of estuarine and marine nurseries for fish and invertebrates. BioScience 51:633-641

Benedetti-Cecchi L, Osio GC (2007) Replication and mitigation of effects of confounding variables in environmental impact assessment: effect of marinas on rocky-shore assemblages. Mar Ecol Prog Ser 334:21-35

Botsford LW, Micheli F, Hastings A (2003) Principles for the design of marine reserves. Ecol Appl 13(Suppl 1: Mar Reserv):25-31

Bussotti S, Denitto F, Guidetti P, Belmonte G (2002) Fish assemblages in shallow marine caves of the Salento Peninsula (Southern-Apulia, SE Italy). PSZN I: Mar Ecol 23:11-20

> Bussotti S, Terlizzi A, Fraschetti S, Belmonte G, Boero F (2006) Spatial and temporal variability of sessile benthos in shallow Mediterranean marine caves. Mar Ecol Prog Ser 325:109-119

> Canals M, Ballesteros E (1997) Production of carbonate particles by phytobentic communities on the MallorcaMenorca shelf, northwestern Mediterranean Sea. DeepSea Res II 44:611-629

Ceccherelli G, Casu D, Pinna S, Sechi N (2006) Evaluating the effects of protection on two benthic habitats at TavolaraPunta Coda Cavallo MPA (North-East Sardinia, Italy). Mar Environ Res 61:171-185

Claudet J, Osenberg CW, Benedetti-Cecchi L, Domenici P and others (2008) Marine reserves: size and age do matter. Ecol Lett 11:481-489

Côté IM, Mosquera I, Reynolds JD (2001) Effects of marine reserve characteristics on the protection of fish populations: a meta-analysis. J Fish Biol 59:178-189

Fernandes L, Day J, Lewis A, Slegers S and others (2005) Establishing representative no-take areas in the Great Barrier Reef: large-scale implementation of theory on marine protected areas. Conserv Biol 19:1733-1744

- Fraschetti S, Bianchi CN, Terlizzi A, Fanelli G, Morri C, Boero F (2001) Spatial variability and human disturbance in shallow subtidal hard bottom assemblages: a regional approach. Mar Ecol Prog Ser 212:1-12

Fraschetti S, Terlizzi A, Micheli F, Benedetti-Cecchi L, Boero F (2002) Marine protected areas in the Mediterranean: objectives effectiveness and monitoring. PSZN I: Mar Ecol 23(Suppl 1):190-200

> Fraschetti S, Terlizzi A, Bussotti S, Guarnieri G, D'Ambrosio P, Boero F (2005) Conservation of Mediterranean seascapes: analyses of existing protection schemes. Mar Environ Res 59:309-332

- Fraschetti S, Terlizzi A, Boero F (2008) How many habitats are in the sea (and where)? J Exp Mar Biol Ecol. 366:109-155

> Garrabou J, Sala E, Arcas A, Zabala M (1998) The impact of diving on rocky subtidal communities: a case study of a bryozoan population. Conserv Biol 12:302-312

Giangrande A, Delos AL, Fraschetti S, Musco L, Licciano L, Terlizzi A (2003) Polychaete assemblages along a rocky shore on the South Adriatic coast (Mediterranean Sea): patterns of spatial distribution. Mar Biol 143:1109-1116

Guidetti P, Bussotti S (2002) Effects of seagrass canopy removal on fish in shallow Mediterranean seagrass (Cymodocea nodosa and Zostera noltii) meadows: a local scale approach. Mar Biol 140:445-453

> Guidetti P, Sala E (2007) Community-wide effects of marine reserves in the Mediterranean Sea. Mar Ecol Prog Ser 335:43-56

Guidetti P, Fraschetti S, Terlizzi A, Boero F (2002) Spatiotemporal variability in fish assemblages associated with coralligenous formations in south-eastern Apulia (SE Italy). Ital J Zool 69:325-331

> Guidetti P, Milazzo M, Bussotti S, Molinari A and others (2008) Italian marine reserve effectiveness: Does enforcement matter? Biol Conserv 141:699-709

> Halpern BS (2003) The impact of marine reserves: Do reserves work and does reserve size matter? Ecol Appl 13(Suppl 1: Mar Reserv):117-137

Halpern BS, Waldbridge S, Selkoe KA, Kappel CV and others 
(2008) A global map of human impact on marine ecosystems. Science 319:948-952

Klein C, Steinback C, Scholz A, Possingham H (2008) Effectiveness of marine reserve networks in representing biodiversity and minimizing impact to fishermen: a comparison of two approaches used in California. Conserv Lett $1: 44-51$

Langlois TJ, Ballantine WJ (2005) Marine ecological research in New Zealand: developing predictive models through the study of no-take marine reserves. Conserv Biol 19: $1763-1770$

Leslie HM (2005) A synthesis of marine conservation planning approaches. Conserv Biol 19:1701-1713

Leslie H, Ruckelshaus M, Ball IR, Andelman S, Possingham HP (2003) Using siting algorithms in the design of marinereserve networks. Ecol Appl 13(Suppl 1: Mar Reserv): 185-198

Maiorano L, Falcucci A, Boitani L (2006) Gap analysis of terrestrial vertebrates in Italy: priorities for conservation planning in a human dominated landscape. Biol Conserv 133:455-473

Micheli F, Halpern BS, Bostford LW, Warner RR (2004) Trajectories and correlates of community change in no-take marine reserves. Ecol Appl 14:1709-1723

> Myers N, Mittermeier RA, Mittermeier CG, da Fonseca GAB, Kent J (2000) Biodiversity hotspot for conservation priorities. Nature 403:853-858

Palumbi SR (2004) Marine reserve and ocean neighborhoods: the spatial scale of marine populations and their management. Annu Rev Environ Resour 29:31-68

Possingham H, Ball I, Andelman S (2000) Mathematical methods for identifying representative reserve networks In: Ferson S, Burgman M (eds) Quantitative methods for conservation biology. Springer-Verlag, New York, p 291-305

Pressey RL, Nicholls AO (1989) Efficiency in conservation evaluation: scoring versus iterative approaches. Biol Conserv 50:199-218

Pusceddu A, Fraschetti S, Holmer M, Mirto S, Danovaro R (2007) Effects of intensive mariculture on sediment biochemistry. Ecol Appl 17:1366-1378

Richardson EA, Kaiser MJ, Edwards-Jones G, Possingham HP (2006) Sensitivity of marine-reserve design to the spatial resolution of socioeconomic data. Conserv Biol 20: 1191-1201

Editorial responsibility: Laura Airoldi, Ravenna, Italy
Roberts CM, Branch G, Bustamante RH, Castilla JC and others (2003) Application of ecological criteria in selecting marine reserves and developing reserve networks. Ecol Appl 13(Suppl 1: Mar Reserv):215-228

- Rondinini C, Boitani L (2006) Differences in the umbrella effects of African amphibians and mammals based on two estimators of the area of occupancy. Conserv Biol 20: 170-179

Sala E, Aburto-Oropeza O, Paredes G, Parra I, Barrera JC, Dayton PK (2002) A general model for designing networks of marine reserves. Science 298:1991-1993

Sale PF, Cowen RK, Danilowicz BS, Jones GP and others (2005) Critical science gaps impede use of no-take fishery reserves. Trends Ecol Evol 20:74-80

Sanchirico JN, Wilen JE (2001) A bioeconomic model of marine reserve creation. J Environ Econ Manag 42:257-276

Shi H, Singh A, Kant S, Zhu Z, Waller E (2005) Integrating habitat status, human population pressure, and protection status into biodiversity conservation priority setting. Conserv Biol 19:1273-1285

Stewart RR, Noyce T, Possingham HP (2003) Opportunity cost of ad hoc marine reserve design decisions: an example from South Australia. Mar Ecol Prog Ser 253:25-38

Stewart RR, Ball IR, Possingham HP (2007) The effects of incremental reserve design and changing reservation goals on the long-term efficiency of reserve systems. Conserv Biol 21:346-354

Tallis H, Ferdaña Z, Gray E (2008) Linking terrestrial and marine conservation planning and threats analysis. Conserv Biol 22:120-130

Terlizzi A, Scuderi D, Fraschetti S, Guidetti P, Boero F (2003) Molluscs on subtidal cliffs: patterns of spatial distribution. J Mar Biol Assoc UK 83:165-172

Terlizzi A, Benedetti-Cecchi L, Bevilacqua S, Fraschetti S, Guidetti P, Anderson MJ (2005) Multivariate and univariate asymmetrical analyses in environmental impact assessment: a case study of Mediterranean subtidal sessile assemblages. Mar Ecol Prog Ser 289:27-42

> Terlizzi A, Anderson MJ, Fraschetti S, Benedetti-Cecchi L (2007) Scales of spatial variation in Mediterranean subtidal sessile assemblages at different depths. Mar Ecol Prog Ser 332:25-39

> Underwood AJ (1995) Ecological research and (and research into) environmental management. Ecol Appl 5:232-247

Submitted: June 20, 2008; Accepted: October 17, 2008

Proofs received from author(s): January 17, 2009 